\title{
EL CONTEXTO Y LOS ACTORES DE LA PRÁCTICA: ESTUDIO SOBRE LA REPRESENTACIÓN DEL PROFESOR EN FORMACIÓN ${ }^{1}$
}

\author{
The context and placement participants: Study on the \\ representation of student teachers
}

http://dx.doi.org/10.22235/pe.v9i2.1296

\author{
GERARDO IGNACIO SÁNCHEZ SÁNCHEZ* \\ XIMENA ELIZABETH JARA AMIGO**
}

Recibido: 07-02- 2016

Revisado: 17-05-2016

Aceptado: 06-07-2016

Resumen. El presente artículo explora las representaciones que 32 profesores en formación reportan sobre el contexto y los actores de la práctica. Los resultados reconocen a la práctica como espacio real de formación y fuente de crisis productiva, y la presencia de dos tipos de actores: aquellos entusiastas y en desarrollo; y los que experimentan a modo de resistencia una frustración profesional. Se adoptó el enfoque cualitativo a partir del tipo estudio de caso

\footnotetext{
${ }^{1}$ Proyecto de investigación financiado por el Plan de Mejoramiento UCM1310 de Formación Inicial de Profesores.

* Profesor de Historia y Geografía. Magíster en política y gestión educacional (Universidad de Talca). Doctor en Ciencias de la Educación (Universidad de la Serena). Académico adscrito al Proyecto de Mejoramiento institucional (PMI 1310) de la Universidad Católica del Maule, Chile. Posee una vasta experiencia en procesos de formación práctica y evaluación del aprendizaje en escuelas y liceos del sistema escolar municipal de la región del Maule, Chile.

** Profesora de Historia y Geografía. Magíster en Curriculum y Evaluación (Universidad Arcis). Doctora (c) en Cultura y Educación en América Latina (Universidad Arcis). Académica adscrita a la Facultad de Educación de la Universidad Autónoma de Chile (Sede Talca). Se desempeña como Secretaria de Estudios de la Carrera de Historia, Geografía y Ciencias Sociales. Posee una experiencia amplia como profesional y coordinadora en programas de Educación Superior.
} 
El contexto y los actores de la práctica: Estudio sobre la representación del profesor en formación

interpretativo, con aplicación de entrevistas semiestructuradas y una estrategia de discusión basada en el análisis temático. La investigación se desarrolló en el campus de una universidad regional de Chile. El estudio abre perspectivas de diálogo en el contexto regional, susceptibles de enriquecer la formación e inserción docente.

Palabras claves. Contexto, actores, práctica, representaciones, Chile

\begin{abstract}
This article explores the representations that 32 student teachers have about the context and placement participants. The results identify the context where the placement is being carried out as a real space of training and production crisis source, and the presence of two types of participants: those who are enthusiastic and under development; and those who experience professional frustration. The qualitative approach was used based on the interpretative case study in which semi-structured interviews and a strategy discussion based on thematic analysis were carried out. The research was conducted on the campus of a regional university of Chile. The study opens up prospects for dialogue in the region, capable of enriching Initial Teacher Training.
\end{abstract}

Keywords: Context, participants, placement, representations, Chile

\title{
INTRODUCCIÓN
}

El estudiante de pedagogía afronta la práctica desde ciertos proyectores conceptuales e imágenes preformativas que le permiten disponer de una percepción aún parcial de la realidad. Esta percepción suele verse tensionada cuando súbitamente, enfrentado al trabajo en aula, constata que nada o muy poco se comporta como estaba previsto. Se ve necesitado entonces de reglas flexibles y cambiantes, que debe descubrir y desarrollar para lograr una compresión situada de la tarea docente, pues la explicación teórica omnisciente presentada en la universidad no le sirve o no le brinda las respuestas. Más aún cuando "una formación profesional que gire, en un principio, en torno a la comprensión y al análisis teórico de la intervención contribuye a retrasar la aprehensión de la 
El contexto y los actores de la práctica: Estudio sobre la representación del profesor en formación

economía pedagógica por el hecho de que incita a realizar una lectura fragmentaria de las situaciones" (Carbonneau y Hétu, 2010, p. 128).

En los relatos que se recogen en reuniones de trabajo con los estudiantes de pedagogía se constata que cada uno posee variadas preconcepciones y expectativas sobre lo que puede ser su aterrizaje al interior de una sala de clases. La pedagogía muchas veces lleva a la idealización del futuro trabajo docente: el amor por enseñar, niños y jóvenes preocupados por su aprendizaje y apoderados comprometidos. Pocos saben la magnitud que puede tener el choque con la realidad y el impacto que este produce en su ser docente. En consecuencia, en la formación de profesores emerge la importancia del trabajo de las representaciones, las que -entendidas como instrumentos de naturaleza cognitiva que facilitan la aprehensión de la realidad-pueden en el caso de los profesores "considerarse como uno de los medios que estructuran su comportamiento de enseñanza y aprendizaje" (Baillauques, 2010, p. 56), más aún cuando se reconoce la íntima relación entre las imágenes/expectativas de la tarea docente y las realidades donde se lleva a cabo.

Conocer la labor docente en su contexto educativo (medio normado, complejo y dinámico) es fundamental en los programas de formación inicial. Durante los años de formación se entregan diversos conocimientos, se desarrollan determinadas habilidades y se propician ciertas disposiciones que son útiles y fundamentales, mas no constituyen la totalidad de lo que se requiere para asumir la tarea. Al interior del aula, el docente se enfrenta a un objeto de estudio, el alumno, que es voluble y variable no solo en aspectos físicos y psicológicos, sino también sociales y culturales (Tardif, 2004). Todo esto se entrelaza con un contexto laboral complejo y diverso, con normativas y cultura propia, donde la interacción con los demás agentes educativos, además de clave, resulta ineludible. Entonces, es en esta instancia donde entran en juego aspectos intrínsecos que nadie ha enseñado instructivamente, pero que están presentes en el individuo: los saberes propios y experienciales, el sentido común y las 
El contexto y los actores de la práctica: Estudio sobre la representación del profesor en formación

experiencias preformativas, que generan una capacidad de adaptación específica que lleva finalmente a un modo de hacer y, por tanto, de representar la docencia.

Debido a la complejidad que representa la formación inicial de profesores, los estudiantes de pedagogía disponen en su itinerario formativo de prácticas tempranas que los aproximan a lo que significa el trabajo docente. Sin embargo, estas visitas deben contar con la reflexión necesaria para que tales experiencias tomen sentido y no se vuelvan vacías en contenido e impacto, además de ayudar al estudiante a entender lo que significa la labor docente. Labor que supone "desencadenar un programa de interacciones con un grupo de alumnos, a fin de conseguir determinados objetivos educativos relativos al aprendizaje de conocimientos y a la socialización" (Tardif, 2004, p. 87). Se desprende de lo anterior que el trabajo docente está afectado por un ambiente de trabajo constituido por las interacciones humanas. Esto conforma el núcleo de la labor del profesor y, por ende, su naturaleza y la de todas sus actuaciones.

Al igual que todo trabajo humano, el trabajo docente posee diversos componentes: finalidad, objeto, resultados, técnicas y saberes de los trabajadores, su papel en el proceso. Estos presionan el hacer, al generar dilemas y tensiones en la trama del trabajo docente. Por un lado, los docentes deben trabajar con un gran grupo de personas, pero a la vez deben diferenciar su acción, pues los alumnos tienen diferentes cualidades y capacidades. Los profesores deben evidenciar el afecto, para motivarlos, pero manteniendo un límite acorde con el papel de mediador. Conjuntamente, el poder del control ejercido sobre el objeto humano es imposible de ser total y completo. En su configuración como ser humano, está afecto a derechos y no puede ser obligado a aprender por sí mismo si no lo desea. En este sentido, uno de los principales problemas del oficio docente es trabajar con un objeto que, de una forma o de otra, escapa siempre al control del trabajador (Tardif, 2004). Esto lleva otra vez a recalcar el poder interpretativo de la labor docente.

Parece fundamental detenerse en la noción de trabajo docente que emerge, pues cualquier propuesta de formación inicial se sustenta en reflexiones y 
El contexto y los actores de la práctica: Estudio sobre la representación del profesor en formación

supuestos acerca de las tareas que los profesores están llamados a desarrollar. En ese sentido, "una concepción comprensiva de la enseñanza supone definiciones diferentes en el plano del diseño de la formación, que apresen la complejidad de la tarea docente y construyan capacidades de intervención que atiendan a tal complejidad" (Diker y Terigi, 1997, p. 98). La formación inicial docente debe ser capaz de liberarse de tradiciones y perspectivas idealistas 0 excesivamente normativas, para anclarse a los requerimientos reales y las condicionantes que configuran el trabajo.

Estas tradiciones entendidas como "configuraciones de pensamiento y acción institucionalizadas, incorporadas a las prácticas y a la conciencia de los sujetos suelen moverse dilemáticamente entre el instrumentalismo y el dramatismo" (Diker y Terigi, 1997, p. 110).

Por un lado, la precaución de que funcionen los dispositivos, de calibrar sus avances, de perfeccionar los métodos y las técnicas, de controlar los resultados, en fin de racionalizar el acto educativo con vistas a una eficiencia mayor; por el otro, la preocupación por aprehender las situaciones singulares, sus múltiples dimensiones y desarrollos con la sensibilidad y el rigor que exige la presencia, la atención, la apertura a lo imprevisto, la regulación de los procesos, la conciencia de lo que se juega, en suma, el sentido del drama educativo (Ferry citado en Diker y Terigi, 1997, p. 100).

Será importante superar la idea de práctica reductible a un conjunto de dispositivos técnicos; pero también de no resignarse a la sorpresa permanente.

Se enfrenta el influjo de dos modelos de formación: el tecnológico y el orgánico. En el primer modelo —en línea con una racionalidad instrumental de medios/fines-, el docente no necesita conocimiento experto sino transformado en competencias comportamentales orientadas a un desempeño. Se considera a la práctica un "campo de aplicación de fórmulas y técnicas concebidas como 
El contexto y los actores de la práctica: Estudio sobre la representación del profesor en formación

universales y verdaderas, en la medida en que se sustentan en conocimientos rigurosos y sistemáticos de base científica" (Davini, 1995, p. 103).

En el segundo modelo — con la puesta en práctica de lógicas "indefinidas, emergentes e interactivas-, la enseñanza constituye una actividad compleja que se desarrolla en escenarios singulares, situados en un contexto histórico-cultural, con resultados abiertos a la incertidumbre y a los conflictos de valor, con una formación centrada en un sujeto, que, reconociendo su hacer, investiga y desarrolla autonomía profesional" (Davini, 1995, p. 103). Este modelo concibe una relación dialéctica teoría-práctica anclada en el papel que desempeña la reflexión en, a partir de y sobre la práctica.

Estas propuestas formativas de distinta naturaleza condicionan necesariamente la comprensión del trabajo docente. En la actualidad, se requiere una formación/docencia en diálogo con el lenguaje de la práctica, es decir, que facilite la tarea de aprender a enseñar, que haga efectiva la apropiación del rol, que permita preparar a los docentes para una determinada pero importante exigencia de la actividad en la enseñanza: su juicio sobre la situación que enfrenta y el desarrollo de su actividad. Por lo tanto, es necesario encontrar estrategias de formación que incorporen elementos de ambas racionalidades, en lo que Diker y Terigi (1997) denominan certeza situada.

Para avanzar en el desafío anterior es preciso superar la formación docente tradicional - que concibe la buena enseñanza como la traducción de la teoría en la práctica - y adoptar nuevas tendencias, que consideran la buena enseñanza como resultado del análisis y reflexión de las características del contexto, junto con la exploración de alternativas para responder a ese contexto. Téngase presente que la profesión docente necesita tanto de "individuos abiertos, capaces de ser originales, de adaptarse de manera creativa y evolutiva y de ser actores sociales, cuanto de funcionarios obedientes y homogéneos respecto a la conservación de valores y conocimientos, y a la aplicación de la disciplina frente a los alumnos" (Baillauques, 2010, p. 84). 
El contexto y los actores de la práctica: Estudio sobre la representación del profesor en formación

El oficio de maestro, "por el hecho de abarcar un conjunto de tareas complejas y de exigir una serie de conocimientos ligados a la experiencia, debe ser enseñado en relación con esta complejidad y por medio de la organización personalizada de los aprendizajes respecto a este conjunto de tareas" (Belair, 2010, p. 106). Ello en razón a la existencia de "zonas indeterminadas de la práctica -tal es el caso de la incertidumbre, la singularidad y el conflicto de valores- que escapan a los cánones de la racionalidad técnica" (Schon, 2010, p. 20).

El espacio que está llamado a facilitar la formación y una adecuada comprensión de la naturaleza del trabajo docente es el de la práctica, entendida como una experiencia de trabajo orientada a promover el cuestionamiento de la teoría a partir del enfrentamiento con problemas educativos y la búsqueda de posibles soluciones. La práctica no se reduce a un dominio de aplicación de teorías externas, es más bien un lugar de constante producción de nuevas soluciones a los problemas con los cuales se ven enfrentados los profesionales. Desde la perspectiva de Orland- Barak y Yinon (2008), es un espacio que permite aprender un lenguaje profesional compartido, un compromiso con la toma de decisiones, lo que favorece la apropiación del contexto y la identificación de los aspectos inmediatos y mediatos del trabajo docente; de ahí la necesidad de no limitar la práctica al aprender a enseñar en el aula, pues ello equivale, en la mirada de Davini (1995), a desestimar sus "dimensiones sociocultural y ético política" ( $p$. 114), y marginar el rol que juegan la subjetividad y los propios marcos interpretativos en la comprensión de los procesos de enseñanza y aprendizaje.

La compresión de la potencialidad formativa de los contextos de práctica resulta clave si lo que se pretende es disminuir el shock de realidad que experimentan los practicantes cuando, en dicho escenario, deben procurar no solo la obtención de conocimiento profesional, sino también un cierto equilibrio personal que permita enfrentar las diversas situaciones que la tarea involucra y tomar frente a ellas sus propias decisiones (Carbonneau y Hétu, 2010). 
El contexto y los actores de la práctica: Estudio sobre la representación del profesor en formación

Queda así de manifiesto la complejidad del trabajo docente, pues supone un proceso de aprender a vincular las situaciones vividas (ficticias o reales) con las teorías que pretenden explicarlas, mediante una estrategia de generalización de los procesos. De lo que se trata es de evitar el "desfase entre una formación académica más bien inservible y una práctica intuitiva que puede resolver los imprevistos y problemas circunstanciales, pero nos da la impresión de un eterno comienzo" (Belair, 2010, p. 105).

El trabajo docente, como trabajo pedagógico, tiene una especificidad y una determinada naturaleza, y se orienta hacia finalidades. "En sí mismo es complejo y contradictorio, en la medida en que supone una relación entre sujetos con experiencias diversificadas y jerárquicamente diferenciadas" (Davini, 1995, p. 53), muy distinto a las visiones tradicionales, según las cuales el docente es una persona que aplica conocimientos producidos por otros o es un agente determinado por mecanismos sociales. Por el contrario, "la compresión de la naturaleza de la enseñanza requiere tener en cuenta la subjetividad de los actores en acción, es decir la subjetividad de los enseñantes" (Tardif, 2004, p. 169), pues el profesor constituye un actor que asume su práctica a partir de los significados que él mismo le da, un sujeto que posee conocimientos y un saber hacer provenientes de su propia actividad, y a partir de los cuales, la estructura y orienta.

Las nuevas demandas al trabajo docente obligan a entender el oficio como "una realización habilidosa, como una experiencia, como una construcción individual a partir de elementos sueltos y hasta contradictorios" (Tenti, 2007, p. 12) al existir una tensión no resuelta entre las exigencias del funcionario (que cumple una función, respeta un reglamento) y las del sujeto actor (autónomo, creativo).

De ahí que esta investigación busque registrar el punto de vista de los profesores en formación, entendidos no como objetos, sino como sujetos y, por tanto, descubrir su subjetividad de actores en acción cotidiana. Se trata de una aproximación según la cual —con base en la fenomenología y los enfoques narrativos - se estudian sus propios relatos y metáforas personales referentes a su trabajo. Específicamente, el artículo tiene como objetivo caracterizar, a partir de 
El contexto y los actores de la práctica: Estudio sobre la representación del profesor en formación

las representaciones del profesor en formación, la importancia que otorga al contexto de la práctica, así como las características de los actores que configuran dicho espacio, para profundizar en el distanciamiento/proximidad entre el campo de la formación inicial y el escenario del ejercicio profesional.

El documento se organiza a partir de una introducción, que sitúa la discusión teórica en torno a la temática y concluye con la formulación de objetivos; la metodología adoptada; los resultados obtenidos; su discusión y las referencias bibliográficas utilizadas.

\section{METODOLOGÍA}

Dada su naturaleza cualitativa, el trabajo opta por la modalidad de estudio de caso, entendido como descripción intensiva, holística, de una entidad singular, un fenómeno o unidad social. Se caracteriza por ser particularista, descriptivo y heurístico, y se basa en el razonamiento inductivo al manejar múltiples fuentes de datos. Los estudios de casos concentran su atención sobre el modo particular en el que grupos de personas confrontan problemas específicos, y adopta una visión holística de la situación.

El presente trabajo asume la tipología de estudio de caso interpretativo (Pérez, 2007), en tanto contiene descripciones ricas y densas, utilizadas para desarrollar categorías conceptuales o para ilustrar, defender 0 desafiar presupuestos teóricos defendidos antes de recoger los datos.

En el marco de un muestreo teórico, y siguiendo a Flick (2007), se utilizan los siguientes criterios de selección de la muestra de estudiantes en práctica: optar por casos típicos, para develar el campo desde dentro y desde su centro; optar por una selección según la intensidad con la que los rasgos, procesos, experiencias interesantes se producen; seleccionar casos que sean de más fácil acceso (conveniencia). 
El contexto y los actores de la práctica: Estudio sobre la representación del profesor en formación

La recolección de información se lleva a cabo a través de entrevistas semiestructuradas, administradas a 32 estudiantes de pedagogía básica que enfrentan su proceso final de práctica y cuya edad promedio es de 23 años.

Dentro de las perspectivas analíticas planteadas por Riessman (2008) se trabaja con el denominado análisis temático, cuyo foco está en el contenido del relato, su relación con recursos lingüísticos y culturales disponibles en esa sociedad o cultura (lo "dicho").

El procedimiento de análisis implica la contextualización y organización de las entrevistas, según frases significativas; identificación de temas y subtemas (elaboración de índice temático); escritura y redacción del análisis por tema.

Las unidades de contenido que se presentan en los resultados corresponden preferentemente a fragmentos de las entrevistas $y$, en algunos casos, segmentos de oraciones a los cuales se les asignó un código que indica iniciales de nombre y apellido, con la intención de facilitar su identificación.

\section{RESULTADOS}

Desde el punto de vista de la presentación de resultados, estos se organizan en dos categorías. La primera, denominada "La potencialidad formativa del contexto de la práctica", refiere a la idea de espacio formativo, sus requerimientos y su valor para la comprensión de la naturaleza del trabajo docente. La segunda se centra en los profesores de aula, entendidos como actores de los espacios de práctica.

\section{La potencialidad formativa del contexto de la práctica}

La práctica está llamada a constituirse en un espacio capaz de favorecer un buen desempeño profesional, al tiempo que permite ir construyendo los cimientos de un ejercicio profesional que se nutra tanto de lo que sucede al interior de la universidad como en el mundo escolar (Correa, Cividini, Fuentealba, 2013, p. 9). 
El contexto y los actores de la práctica: Estudio sobre la representación del profesor en formación

\section{Espacio de formación}

La representación de los profesores en formación emerge en la idea de una práctica definida como contexto de formación, validada progresiva y crecientemente, en tanto espacio implicante que los afecta y modifica en términos de aprendizajes y experiencia.

Esto es reconocido a partir de expresiones del tipo: "conocer la realidad a la cual me veré enfrentado en el reto de convertirme en profesor" (M. J. C.); "lugar donde se deja de manifiesto las propias capacidades" (V. C.); "permite reconocer las implicancias de la profesión" (O. H.); "un papel relevante dentro de la conformación como profesor" (A. H.); "entrega las nociones sobre el contexto en que tendré que desarrollarme como profesor" (J. H.); "permite ir teniendo contacto con la realidad educativa" (R. C.) y, desde un punto de vista más personal, "ayuda a conocer nuestras fortalezas y debilidades como profesor en formación" (D. I.); "potenciar y/o mejorar nuestras capacidades" (I. I.); "posibilita enfrentarme a mis propias fuerzas y temores" (F. C.).

En consecuencia, la práctica se configura como un espacio donde se completa la formación inicial, que permite vivir la experiencia de ser profesor antes de ingresar al campo laboral, en un ejercicio orientado a reconocer las propias potencialidades en juego.

Entendido como contexto de la formación y el trabajo docente, asumiría así un carácter decisivo, en tanto espacio de articulación de teoría y práctica, siempre mediado por un encuentro profesional que se asume desde lo que se es como persona:

Teoría y práctica son dependientes una de otra. La formación práctica te enfrenta directamente a todos tus temores presentes como futuros. Es un espacio decisivo donde se pone a prueba lo que se sabe y conoce, se pone en acción todo tipo de conocimiento, ya sea experiencial, cognitivo, actitudinal, procedimental (R. C.). 
El contexto y los actores de la práctica: Estudio sobre la representación del profesor en formación

\section{Requerimientos}

En relación a los requerimientos que supone este espacio curricular, para posibilitar el normal desarrollo de la formación, la representación de los entrevistados emerge en la idea de una práctica en relación con la teoría, pero dejando claro que se trata de un trabajo donde no basta la teoría:

Soy de los que piensan que la práctica debe ir acompañada de la teoría, ambas deben caminar al mismo tiempo, aunque no siempre resulte fácil. Pero cuando de práctica se trata, su lugar en la formación es fundamental o principal, puesto que es la base para formar al profesor. Esta nos ayuda a adquirir experiencia y lograr tener una visión aterrizada del trabajo (L. C.).

La formación práctica es fundamental, es el espacio donde la teoría adquiere sentido, además de que es esta la que nos hace descubrir realmente lo que es la docencia (F. C.).

Otro requerimiento reconocido refiere a estructura y funcionamiento, pues conciben la práctica como un espacio de formación progresivo y necesitado de acompañamiento, en la tarea de conocer y comprender la dinámica de aula sobre la cual se interviene:

Importante, es parte del proceso de formación profesional, es esencial que sea progresiva, donde primero exista una aproximación, luego una inserción y finalmente la aplicación. Pienso que es fundamental y decisiva para poder defenderse y enfrentarse a la realidad diversa y compleja del aula (J. E. H.).

Es necesario para poder realizar una buena práctica poder tener un apoyo sólido en que respaldarse, y ese apoyo lo entrega la 
El contexto y los actores de la práctica: Estudio sobre la representación del profesor en formación

formación profesional teórica y el acompañamiento, que es parte del proceso requerido para ser docente (J. H.).

\section{Potencialidad}

Respecto a la potencialidad que presenta como espacio formativo, los entrevistados desarrollan representaciones de valoración en la línea de comprensión del trabajo docente, valoración de la pedagogía y fuente de experiencia.

Facilita la comprensión del trabajo docente, toda vez que, en primer lugar, posibilita la constatación de la realidad, en segundo lugar, proporciona el contexto real donde se lleva a cabo el trabajo docente y, en tercer lugar, permite entender el trabajo que se espera desarrolle todo profesor:

Uno se encuentra con la realidad misma, la vive y la intenta afrontar poniendo en acción diversas herramientas (C. C.).

La práctica es una instancia que me entrega las nociones sobre el contexto en el cual tendré que desarrollarme como profesor. Gracias a ella puedo evidenciar el qué y cómo enseñar, o de qué forma puedo desarrollar la enseñanza para el aprendizaje de mis estudiantes. No obstante, la práctica es la etapa en la cual el docente en formación podrá ver las patologías que se manifiestan en el aula, generando así la posibilidad de reflexionar sobre cómo enfrentar su labor como docente, lo que ayudará a formar su carácter, algo vital para el desarrollo profesional (J. H.).

Gracias a la formación práctica logré entender que el éxito del trabajo se relaciona con las interacciones que logro con mis estudiantes, cómo hago para que las actividades en la sala de clases motiven al estudiante al aprendizaje. No solo necesito manejar el contenido. Al estar en práctica me di cuenta de que se 
El contexto y los actores de la práctica: Estudio sobre la representación del profesor en formación

trata de un trabajo de generación de vínculos y relaciones (M. A. C.).

Favorece la valoración de la pedagogía, vale decir la especificidad de la tarea docente, al ayudar a descubrir el sentido de lo que significa ser profesor.

En coherencia con lo anterior, surgen representaciones que la valoran en tanto les permite el descubrimiento de la tarea docente:

Es un complemento a la formación teórica, ocupa el primer lugar, pues ahí el aprendizaje toma sentido, es donde uno realmente se da cuenta si será capaz de enfrentar la realidad de los distintos centros educativos y los diferentes perfiles de estudiantes (M. P. І.).

Por otro lado, explicitan una alta valoración del espacio en tanto permite la confirmación vocacional, con un trabajo que supone la atención al estudiante y los mecanismos que hagan posible su aprendizaje:

En la práctica también pude comprobar de mejor forma lo que era ser profesor, antes de ella mi visión era más bien romántica o muy centrada en el deber ser o en el estudio de las disciplinas, ahora entiendo su sentido y proyección, pero sobre todo su complejidad y demandas (V. C.).

En un plano más operativo, consideran que la práctica tiene un valor en relación a la vocación, ya sea para fortalecerla o debilitarla, dado el acercamiento que significa hacia los estudiantes, la tarea, los contextos, la cultura del ser profesor: 
El contexto y los actores de la práctica: Estudio sobre la representación del profesor en formación

El lugar en que ubico la formación práctica es contradictorio o, por llamarla así, ambivalente, puesto que lo extraído como información vital fueron los "antiejemplos" o, en un lenguaje directo, lo que no se debe hacer como docente, porque las prácticas observadas por parte del docente guía eran desapasionantes, desalentadoras y con la facultad de quitar cualquier ápice de espíritu a favor de la disciplina, ya que lo único que motivaba a los alumnos era su rigidez, pero a la vez está la capacidad de detectarlo y promover el cambio, por lo menos personal (D. C.).

No sé si hablar de "un lugar", pero debo admitir que la formación práctica es sumamente relevante, te ayuda a disipar tus miedos, a aprender de tus aciertos y errores, te ayuda a fortalecer o debilitar tu vocación, a saber si es eso lo que realmente quieres (P. C.).

Se constituye en una fuente de experiencia en el aprendizaje de ser profesor. Constituiría, desde el punto de vista personal, un espacio generador de experiencia, que permite poner en acción lo aprendido en la formación inicial y a la vez aprender, desde el hacer, la observación y reflexión que genera la visita a los centros educacionales y el verse enfrentados a la multiplicidad de tareas y a la inmediatez con que todo ocurre en la sala de clases.

Más específicamente, los relatos aluden a la posibilidad de probar lo aprendido y aprender:

Es el lugar donde se ponen en juego mis propias creencias, donde puedo probar lo aprendido, pero, a la vez, aprender lo que antes no había podido conocer. Es un lugar clave para el aprendizaje y fuente de crisis productiva desde la cual se avanza y se plantean nuevos retos en relación a la enseñanza y el aprendizaje (V. C.). 
El contexto y los actores de la práctica: Estudio sobre la representación del profesor en formación

Facilita al estudiante de pedagogía aproximarse a los saberes prácticos, aprender y adquirir experiencia, en una visión aterrizada de las tareas:

Puesto que es la base para formar al profesor en formación. Esta nos ayuda a adquirir experiencia y lograr tener una visión aterrizada de las cosas, para operar en ese sentido (L. C.).

Le otorgo un lugar fundamental, ya que no sirve de mucho aprender desde la teoría sin integrar esos conocimientos a la realidad de la sala de clases, ya que el contexto de cada colegio es diferente, además de que la práctica nos da la experiencia y la experiencia nos debe llevar a ser mejores profesionales (C. C.).

Es experiencia en lo que refiere a ellos como sujetos que se aproximan a su objeto de estudio y de trabajo y, por tanto, también conocimiento de la profesión en la medida en que tienen la posibilidad de ejercitarla, vivenciarla:

Es en la práctica donde uno coloca a prueba todo lo aprendido $y$, lógico, siempre van a existir deficiencias en el aspecto profesional. Un docente debe estar constantemente perfeccionándose, esto lo he comprobado con la práctica y la necesidad constante de volver a estudiar (G. C.).

Un lugar importante, en la medida en que está conectada con una teoría fundamental que ayuda a comprenderla. Una práctica sin teoría termina en activismo en el aula, hacer por hacer sin tener claro para qué se enseña ni mucho menos a quién se enseña ( $P$. C.).

La práctica ocupa uno de los principales lugares dentro de la formación docente. 
El contexto y los actores de la práctica: Estudio sobre la representación del profesor en formación

Si bien es cierto que en los ramos que cursamos en la universidad aprendemos lo básico para desarrollarnos posteriormente como profesores, es con la práctica en los colegios en donde recién empezamos a actuar y pensar como profesores, ya que es aquí en donde nos enfrentamos a un contexto real y las mismas consecuencias de nuestras acciones nos van mostrando si hemos tomado decisiones correctas o no, lo cual abre paso a reflexionar sobre cómo ir mejorando, cosa que no sucede frecuentemente cuando estamos en clases teóricas en la universidad en donde toda reflexión termina en la nota que define si lo hicimos bien o mal (A. C.).

\section{Los profesores de aula como actores de los espacios de práctica}

En esta categoría, las representaciones de los entrevistados se orientan a caracterizar a los profesores del sistema escolar en tanto actores que guían el proceso de inserción a la práctica profesional.

Toda profesión se apoya en tres ámbitos: técnico, artístico y moral. El ámbito técnico-artístico engloba el saber y el ser capaz de llevarlo a cabo y de transmitirlo, con las destrezas necesarias que esto exige. Pero, además, exige incluir la responsabilidad personal de cada educador, lo que supone sobre todo "un deber de actuar de tal manera que, por encima de cualquier otra valoración, se lleve a cabo aquello que beneficia a los alumnos" (Wanjiru, 1999, p.40).

Ante ese escenario, las representaciones de los entrevistados emergen en la idea de enfrentarse a una diversidad de profesores que, al igual que la vida, no pueden ser reducidos a disyuntivas dicotómicas y despiertan en ellos sentimientos de proximidad o distancia en su proceso de formación y de construcción de identidad. 
El contexto y los actores de la práctica: Estudio sobre la representación del profesor en formación

Estos profesores son reconocidos en expresiones de tipo buenos y malos; aquellos que se mueven por la rutina y los que buscan innovar, en definitiva, variados.

\section{Los buenos}

El calificativo de los buenos profesores se encuentra asociado a representaciones sobre docentes que manejan lo que enseñan, preocupados por sus estudiantes y capaces de construir relaciones con ellos:

Personas muy sabias, saben qué hacer y cómo hacer en cada situación que se enfrentan en la sala de clases, entretenidos y activos cuando hacen sus clases, generosos y colaborativos con los nuevos profesores en formación (D. I.).

Los excelentes, aquellos que modelan y dejan huellas pues favorecen el aprendizaje (I. C.).

Se trataría de profesores reconocibles por una serie de cualidades personales, que facilitan el encuentro y el vínculo con los estudiantes del sistema escolar:

Profesores muy cercanos, amigables, confiables, capaces de acoger al novato (P. C.).

Acogedores, cercanos con los alumnos, preocupados por las clases y los alumnos, responsables, dispuestos a guiar (A. C.).

\section{Los malos}


El contexto y los actores de la práctica: Estudio sobre la representación del profesor en formación

El calificativo de malos profesores se vincula con prácticas pedagógicas que no favorecen el modelaje positivo, e incapaces de construir relaciones formativas con los estudiantes.

En el primer caso, las representaciones aluden a profesores que se constituyen en antiejemplos, por lo que hacen y comunican en el aula:

Ha sido decepcionante encontrarme con profesores a los cuales no les es importante el aprendizaje y por lo tanto los estudiantes (C. C.).

Desilusionados y cansados del trabajo como docente, monótonos cuando hacen sus clases, sin vocación, solo hacen su trabajo (D. I.).

Emergen aquellos profesores conformes con un trabajo que buscan cumplir, sin necesariamente responder a las necesidades de los estudiantes:

Y los que lo llevan a cabo en forma mediocre, sin interés por sus estudiantes y lo que estos aprenden (L. C.).

Hay una disposición de los profesores que se traduce en la generación de ambientes tensos de trabajo en el aula:

Generan ambientes tensos, egoístas y extremadamente dañinos para el proceso de enseñanza-aprendizaje de los estudiantes, haciendo del trabajo docente algo cada día más agotador (V. C.). 
El contexto y los actores de la práctica: Estudio sobre la representación del profesor en formación

También hay un escaso manejo del contenido disciplinario como para arriesgar en términos de las propuestas metodológicas que ofrecen a sus estudiantes:

Con poco dominio del contenido en el caso de cursos de básica debido a la amplia gama de subsectores que manejan (O. C.).

Las representaciones de los entrevistados perfilan la presencia de profesores individualistas, que no generan colaboración en el trabajo con pares o en la relación con el estudiante en práctica.

Competitividad entre ellos, más que dispuestos a apoyarse para enfrentar los desafíos del aula y las necesidades de los estudiantes (B. H.).

El gremio se caracteriza porque ninguno quiere ser menos que el otro, y sobresalir en desmedro de un colega es una opción legítima, enseñada éticamente por pocos y practicada realmente por muchos (I. H.).

Se muestran competitivos, con escasa práctica de un trabajo verdaderamente colaborativo. No confían en la educación, no creen en ella (C. L. C.).

\section{Rutina}

En esta categoría, las representaciones de los entrevistados aluden a la existencia de profesores con actuaciones aferradas a un hábito que se resiste a cambiar, y que los frena ante la posibilidad de probar nuevas estrategias o formas de actuación: 
El contexto y los actores de la práctica: Estudio sobre la representación del profesor en formación

Se está entre personas con experiencia, a los cuales esta ha tratado peor, fueron devorados por la rutina y el desencanto (G. C.).

Sin ganas de cambiar o aprender nuevas metodologías o formas de trabajo (A. H.).

Se constituyen en profesores con una tendencia a caer en modelos de enseñanza de corte tradicional, en términos de las estrategias metodológicas que utilizan, con patrones de interacción en aula basados en la exposición del profesor, el abuso del trabajo con guías y el texto escolar, que buscan la mantención de una permanente actitud de escucha del estudiante:

Pero siempre de metodología tradicional, siendo las clases mayormente expositivas (N. I.).

No creo que se diferencie mucho del antiguo dictado o del transcribir lo del libro al cuaderno (A. C.).

La mayoría solo utiliza el libro del estudiante (lectura y responder las preguntas), en el mejor de los casos utilizan diapositivas, pero esto se utiliza para que los alumnos copien la materia (A. C.).

El profesor habla y los alumnos escuchan, usan todo el semestre la misma metodología, guías, lecturas, responder las actividades del libro de clases (K. C.).

Se trataría de profesores que, anclados a modelos didácticos que aprendieron en algún momento de su formación o ejercicio profesional, reproducen actuaciones basadas en la sanción hacia sus estudiantes: 
El contexto y los actores de la práctica: Estudio sobre la representación del profesor en formación

Tienen poco interés por que los alumnos aprendan (J. A. H.).

Buscan reproducir una educación basada en el rigor y castigo (C.

H.).

Con una actitud de pasividad frente al sistema y las posibilidades de dinamizarlo, en términos de su funcionamiento e impacto, que llega incluso a naturalizar esta situación con resignación en algunos casos y con resistencia soterrada en otros:

Los describiría como pasivos y conformes con el sistema (A. C.).

Personas que siguen la inercia del mercado (J. H.).

No he visto en ellos deseos o ansias reales de obtener mejores resultados con sus estudiantes (M. C.).

Están los profesores que, en sus actuaciones y expresiones, parecen cansados del trabajo docente y de la tarea permanente de comprender a los estudiantes, a objeto de ser asertivos en sus decisiones:

Parecen cansados de dedicar tanto tiempo en el trabajo (A. C.).

Profesores cansados por todo el trabajo que deben realizar (K. C.).

Están agobiados y esperando jubilarse, se muestran cansados y lo verbalizan (J. A. H.).

Se muestran ocupados en conservar su trabajo y renuncian a la posibilidad de innovar o transformar su práctica pedagógica: 
El contexto y los actores de la práctica: Estudio sobre la representación del profesor en formación

Sino por el contrario, he visto manifiesta la actitud de "cumplir" con lo que se les ha pedido y nada más, eso es todo, con eso se ven conformes (M. C.).

Desde profesores de desempeño bastante discreto, sin mayor interés por los logros de los objetivos (F. C.).

La consecuencia final de este desgaste evidenciado por los profesores se traduce en la dificultad para lograr contener a los estudiantes y orientarlos al compromiso con el aprendizaje:

Observo a profesores con mucho desgaste, desánimo, no logran un manejo adecuado con las nuevas generaciones de alumnos ( $O$. C.).

Son profesores que terminan por refugiarse en frases que evidencian una escasa responsabilidad individual en lo que se hace y finalmente se logra, en términos de aprendizaje:

Se escudan tras frases como "el colegio no me apoya", "el director no me apoya", "estos cabros son más flojos", "la familia no está ni ahí con sus hijos", en fin, siempre hay excusas (R. C.).

\section{Innovadores}

En esta categoría, las representaciones de los entrevistados aluden a la existencia de profesores comprometidos con la tarea, capaces de comprender y actuar en los contextos donde operan, sensibles a las necesidades de sus estudiantes y al imperativo de lograr el aprendizaje. 
El contexto y los actores de la práctica: Estudio sobre la representación del profesor en formación

En un crisol, están los profesores con ímpetu de desarrollo profesional:

Se está entre personas con experiencia, a los cuales esta los ha tratado mejor, docentes con hambre de desarrollarse y explotarse profesionalmente (G. C.).

Aquellos conscientes de que su trabajo tiene sentido:

La actitud frente a colegas y alumnos reside en si sienten que su trabajo sirve y es valioso (V. C.).

Los que, en consecuencia con sus principios y reconociendo los contextos de trabajo, buscan avanzar, mejorar dentro de lo que sea posible:

Están los profesores que realizan su trabajo lo mejor posible dentro de sus posibilidades y condicionantes (L. C.).

Dedican más tiempo para trabajar y tienen la voluntad de ayudar (A. H.).

Su dedicación y motivación se nota en cada cosa que hacen. Aun cuando son totalmente ignorados (R. C.).

Profesores que han observado, comprendido e incidido en los contextos de inserción con propuestas formativas pertinentes:

Muchos logran responder a las inquietudes del contexto (A. H.).

Se adaptan a las realidades de sus estudiantes (J. H.). 
El contexto y los actores de la práctica: Estudio sobre la representación del profesor en formación

Comprometidos en un trabajo que tiene sinsabores, y en el cual se busca perseverar a pesar de la adversidad:

Los puedo describir como personas que quieren su trabajo, a pesar de los altos y bajos que pueda conllevar su trabajo en aula (S. H.).

Profesores que luchan día a día por un mejor futuro para aquellos a los que están enseñando (R. C.).

Siguen innovándose y luchando por sus estudiantes. Su esencia denota una gran vocación por lo que hacen, y han aceptado la realidad de los profesores en la actualidad (J. H.).

Se advierte la presencia de profesores que se constituyen en modelo de actuación para los practicantes y para los estudiantes del sistema escolar, al desplegar capacidades profesionales y características personales positivas:

Hasta profesores modelos de los se puede aprender bastante, imitando sus cualidades más destacadas, para hacerlas mías y sacarles provecho (F. C.).

Profesores con vasta experiencia, que están comprometidos con su condición de formadores y a pesar de sus años de servicios ( $\mathrm{J}$. H.).

Algunos tienen vocación y se les nota en el desarrollo de sus clases y cómo se relacionan con los estudiantes (R. C.).

\section{Variedad}


El contexto y los actores de la práctica: Estudio sobre la representación del profesor en formación

Finalmente, la mayor parte de las representaciones de los entrevistados, cuando refieren a los profesores del sistema escolar, se grafican en la expresión de variados. Los entrevistados se manifiestan conscientes del influjo, explícito o implícito, que sobre ellos generan estos diversos perfiles.

Nos encontramos con profesores tan diversos como los estudiantes, desde aquellos muy preocupados y comprometidos hasta llegar a aquellos que se ven cansados y desencantados de todo (S. H.).

Podría describir a los profesores como variados. Esta variedad es lo que más me gusta, ya que cada uno ha elegido esta posición (G. C.).

Muy diversos en sus manejos y compromisos con la docencia, todos tenemos una vida que no merece ser contada en pocas palabras (F. C.).

Enfrentado a esta diversidad de profesores que se encuentran en la escuela está el reconocimiento de que, desde distintos frentes, cada uno de ellos intenta reclutar e influir en el profesional en formación:

Cada grupo intentará reclutarte contándote experiencias y reflexiones (V. C.).

En este sentido, son profesores de aula que, enfrentados a la complejidad del trabajo con alumnos y la diversidad de los contextos, requieren ayuda, aun cuando no siempre lo reconocen: 
El contexto y los actores de la práctica: Estudio sobre la representación del profesor en formación

Más que aceptar a un alumno para guiarlo parecen aceptarnos porque necesitan ayuda urgente (A. C.).

Por consiguiente, se trataría de profesores necesitados de mayor manejo tecnológico, desde el cual puedan nutrir su metodología y relación con los estudiantes:

No saben usar las tecnologías, abusan de ella en muchas ocasiones (C. L. C.).

Desde el punto de vista social, son profesores que han vivido y experimentan, en sus juicios, la escasa valoración que la sociedad muestra respecto al trabajo desarrollado. Esto se constituye en una fuente de desánimo y gatilla mecanismos de resistencia ante un panorama que se advierte crecientemente complejo y que también se ve amenazado por la precariedad de las condiciones de operación que rodean el trabajo docente.

$Y$ con tristeza frente a que nadie ve lo que se esfuerzan por lo que hacen (A. H.).

Principalmente cómo el ámbito laboral muchas veces no entrega las garantías o satisfacciones a las que aspira (O. H.).

El magisterio tiene menoscabada su autoestima y responden al péndulo del trabajo y la subsistencia laboral (J. H.).

Solo quieren que les suban el sueldo, no tienen autoestima, desvalorizan su trabajo (C. L. C.).

\section{DISCUSIÓN}


El contexto y los actores de la práctica: Estudio sobre la representación del profesor en formación

Los enfoques actuales de formación, al propiciar el desarrollo de competencias que han de manifestarse en escenarios auténticos de ejercicio profesional, otorgan un sentido nuevo a las prácticas, en tanto contexto en que el estudiante tiene la posibilidad de combinar diversos conocimientos, habilidades, destrezas, disposiciones y cualidades para comenzar a asumir progresivamente sus tareas profesionales. En ese sentido, "las prácticas, al interior de un programa de formación, contribuyen grandemente a la profesionalización del futuro docente, preparándolo a la vez a la inserción profesional" (Correa, Cividini y Fuentealba, 2013, p. 10).

Desde el punto de vista de sus potencialidades, estos espacios de práctica están llamados a contribuir a la socialización profesional, a la integración de saberes de distinta naturaleza, a la confrontación de modelos de actuación y a lograr, en definitiva, una auténtica comprensión de la naturaleza del trabajo docente.

En coherencia con ello, los diversos proyectos para el fortalecimiento de la formación docente - financiados por el Ministerio de Educación en Chile- han otorgado centralidad a las prácticas de iniciación, a lo largo de toda la formación inicial, orientadas a permitir a los estudiantes de pedagogía ingresar paulatinamente al ámbito escolar y establecer vinculaciones con los saberes profesionales aprendidos en su formación universitaria (Ávalos, 2003).

Estas prácticas enfrentan el desafío de superar la escisión entre dos espacios con potencialidad formativa. Por una parte, la universidad, donde los criterios de rigor pasan por la calidad académica y la capacidad teórica. Por otra, el espacio de la escuela, donde una racionalidad más práctica exige flexibilidad, apertura y manejo de la incertidumbre.

De acuerdo a Ávalos (2003) la práctica docente se entendería como:

El eje que articula todas las actividades curriculares de la formación docente, de la teoría y de la práctica. Su objetivo es permitir la aproximación gradual de los estudiantes al trabajo 
El contexto y los actores de la práctica: Estudio sobre la representación del profesor en formación

profesional, y al mismo tiempo facilitarles la construcción e internalización del rol docente. En forma más precisa, su finalidad es facilitar el proceso por el cual los futuros profesores construyen conocimiento pedagógico, desarrollan en forma personal teoría y práctica de la enseñanza y el aprendizaje y, sobre todo, aprenden a enseñar. Se postula que del modo como se organicen las experiencias de práctica dependerá el grado en que cada futuro profesor o profesora precise su rol profesional en el contexto de la comunidad, escuela y aula, aprenda a diagnosticar los problemas propios de esa situación y a buscar y poner a prueba soluciones (p.109).

Los resultados de la investigación confirman la existencia de una práctica que se articula como contexto de formación, en el que se movilizan diversidad de actores que configuran una trama de interacciones.

Un contexto referido a una práctica entendida como proceso de inmersión, en diferentes niveles de profundidad, en situaciones y espacios característicos de la profesión a desempeñar. Dotadas de un fuerte criterio de realidad y orientadas al aprendizaje profesional, las prácticas permiten al estudiante aproximarse a un espacio que les plantea los problemas de la profesión de forma integrada y no de manera parcelada o normativa, como suele ser la formación universitaria. Esta acción se encuentra sostenida en un cuerpo teórico de conocimientos y requiere de un período de formación académica. Proporciona un saber que permite encaminar a los estudiantes hacia la deliberación para intervenir profesionalmente en la compleja vida del aula y de la escuela.

Unos actores que, situados en el espacio real de ejercicio de la profesión, se perfilan diversos en su nivel de competencia, en sus expectativas y en la pasión que evidencian en la tarea, lo que ejerce en todos los casos distintos influjos sobre su objeto de trabajo directo, como son los alumnos del sistema, y sobre ellos como profesores en formación. 
El contexto y los actores de la práctica: Estudio sobre la representación del profesor en formación

$\mathrm{Y}$, finalmente, una trama que, junto con surgir de la interacción entre el contexto y los actores, se encuentra articulada y tensionada por la precariedad de los contextos, el perfil desbordante de los estudiantes y la complejidad de una tarea que debe ser adecuadamente comprendida para desarrollarla en coherencia.

Para arribar a una mayor comprensión de las vías que llevan a una adecuada formación/trabajo docente, surge la necesidad de detenerse en las representaciones de la tarea. Para quien se enfrenta al desafío de la docencia, las representaciones constituyen instrumentos cognitivos de aprehensión de la realidad y de orientación de las mismas conductas. Desde el punto de vista de las representaciones, estos profesores en formación constatan que su inserción al contexto de la práctica y su enfrentamiento a los actores de la institución educativa les permiten sensibilizarse frente al trabajo docente, cuyas características y naturaleza refieren tanto a sus aspectos relacionales como a la técnica de la enseñanza, a la luz de un perfil de estudiante del cual se es consciente en términos de determinadas características que lo definen.

Para los entrevistados, enseñar es ante todo una práctica: una actividad en clase. $\mathrm{Y}$ el profesor es un personaje central en esta actividad y para esta modalidad, con su estilo y su forma de ser propios. Las otras dimensiones del oficio -las relaciones con los colegas, los aspectos institucionales, las presiones, así como las finalidades sociales- comienzan a ser también descubiertas como parte de su inserción en la práctica. En coherencia con lo que reporta la evidencia empírica, "no solo aprende los contenidos y las conductas útiles para un mejor dominio de su trabajo, sino que, en cierto modo, también se enseña a sí mismo durante su trabajo en todo lo referente a este" (Baillauques, 2010, pp. 67-68).

En relación al contexto de la práctica, el enfrentar situaciones dotadas de complejidad, inestabilidad y demandas crecientes les permite, a los profesores en formación, comprender la verdadera trama del trabajo docente, con una fuerte interpelación del sujeto respecto a lo que este es, sabe y hace. En consecuencia, las representaciones en torno a la práctica emergen asociadas a la idea de 
El contexto y los actores de la práctica: Estudio sobre la representación del profesor en formación

espacio formativo por antonomasia, en tanto es el que hace descubrir realmente lo que es la docencia y constituye una fuente de crisis productiva, pues es el espacio en donde se aprende a actuar y pensar como profesor, un contexto real que los enfrenta a la complejidad de las tareas, al imperativo de tomar decisiones y reflexionar sobre su impacto.

Es importante constatar cómo estos profesionales en formación también experimentan la tendencia a considerar la formación inicial como demasiado teórica y distanciada de la realidad. Enfrentados a un trabajo en aula que los tiende a sobrepasar, manifiestan una diversidad de reproches hacia la formación: sea porque no se les advirtió lo suficiente sobre las dificultades que deben enfrentar, sea por la escasa información respecto a un perfil de estudiantes muy distinto al declarado desde los enfoques psicológicos estudiados en el aula universitaria, o por la escasa preparación para actuar en contextos socioculturales de vulnerabilidad en términos de las oposiciones que encuentran, así como la existencia de profesores del sistema que resisten al cambio y al autocuestionamiento, de actitud poco colaborativa y de rechazo a la teorización. En consecuencia, los resultados de la investigación muestran el shock de realidad que experimentan los profesores en formación en su inserción al aula real, y la crisis que experimentan algunas de sus representaciones de la docencia.

En sus primeras experiencias de enseñanza durante las prácticas, afrontan una serie de proposiciones de manera dilemática, tales como "conocimiento teórico versus conocimiento práctico, academicismo versus socialización, intervención regulada versus reflexión crítica, comprensión situacional versus comprensión situacional holística" (Fernández-Cruz, 2008, p. 71).

La dificultad de las proposiciones dilemáticas comienza a visualizarse cuando enfrentan el acto de enseñar, al constatar que este supera la sola transmisión de contenidos y la planificación previa, pues tal como lo confirma la teoría, "la comunicación verbal en clase, las interacciones, la relación y la variedad de acciones en situación serán las que permitirán, o no, que alumnos diferentes aprendan en cada intervención" (Altet, 2010, p. 39). 
El contexto y los actores de la práctica: Estudio sobre la representación del profesor en formación

Su trayecto por la práctica les permite situarse en contextos reales, desde los cuales logran la comprensión de la tarea docente y el influjo que en ella tienen las características/cualidades de los actores a los que se enfrentan. Cuando refieren a los profesores del sistema, reportan la variedad de perfiles en relación a la comprensión y compromiso con la tarea formativa. Advierten la presencia de al menos dos tipos de profesores: aquellos entusiastas y en desarrollo; y los que comienzan a experimentar una fuerte frustración profesional, que da lugar en algunos casos al descompromiso o a la resistencia más o menos soterrada. En ambos casos, el influjo hacia ellos tensiona fuertemente las representaciones de la tarea y lo que significa ser profesor. En el primer caso, observan a profesores en período de competencia y aceptación reconocida en la comunidad escolar, en el que hay un alto grado de satisfacción personal y organizativa en el trabajo. En el segundo caso, profesores que, por falta de apoyo, por desilusión con la dificultad de la enseñanza o por falta de reconocimiento, han dejado de mirar proyectivamente su trabajo (Day, 2006). Reconocen con fuerza que, en estos profesores, el compromiso tiende a desaparecer, y los interpela a ellos como profesores en formación, respecto a mantener las expectativas, la pasión o el compromiso.

Lo anterior se corresponde altamente con la investigación, en tanto los profesores que están presionados por todas partes — por los alumnos, los padres, los medios de comunicación o las nuevas iniciativas curriculares- sienten la tentación de entrar en una espiral descendente de expectativas y práctica.

El imperativo, a pesar de las dificultades, es resistir la tendencia hacia el escepticismo, buscar y hallar incentivos y recompensas en las cambiantes realidades de la enseñanza (Day, 2006, p. 191).

Esta faceta de los actores del sistema escolar es la que explica o es reforzada por la escasa valoración social del profesorado y su trabajo. 
El contexto y los actores de la práctica: Estudio sobre la representación del profesor en formación

Por otro lado, las representaciones ponen de manifiesto el carácter complejo de la tarea, asociada a su componente relacional que demanda en lo personal y no solo en lo profesional. Se constata el influjo de sus experiencias preformativas y cómo sus propias características personales condicionan el ejercicio de la tarea; y despierta la conciencia creciente de generar un proyecto formativo capaz de responder a un perfil de estudiante que, en lo real, tiende a superar las nociones teóricas, normativas o declarativas presentadas en la formación inicial.

Desde la perspectiva de los entrevistados, se advierte la llegada al aula de una nueva idiosincrasia de jóvenes, con patrones de comportamiento transmitidos por los medios de comunicación que los hacen actuar de manera muchas veces estereotipada, que atenta contra una postura de desarrollo, de consciencia, empatía o valores positivos. Este nuevo perfil tiende a confundirlos respecto a si estos jóvenes actúan autónoma o heterónomamente. Constatan, además, que este perfil de estudiante es capaz de ofrecer una férrea resistencia a lo que pretende enseñar el profesorado y la escuela, lo que sería una de las razones que explicaría la diversidad de profesores del sistema escolar, y con los cuales tienen la posibilidad de interactuar para constatar la complejidad de la tarea docente.

La experiencia de lo que significa enfrentarse al contexto y los actores de la práctica constituye "un proceso contextualizado y situacional en el que la interpretación de cada acontecimiento singular, a la luz de los esquemas de actuación conformados de manera previa, origina nuevos modos de actuación válidos en el contexto práctico de referencia" (Fernández-Cruz, 2008, p. 67).

En ese sentido, la práctica los aproxima a una visión del trabajo docente entendido como "situación contextualizada, compleja, incierta, de enseñanzaaprendizaje con una finalidad precisa, en donde se realizan las tareas del maestro con unos alumnos específicos" (Altet, 2010, p. 39). En esa intersección, los estudiantes en práctica comienzan a reconfigurar y confirmar una comprensión más situada de la tarea docente, al verse enfrentados a las confusiones que les 
El contexto y los actores de la práctica: Estudio sobre la representación del profesor en formación

provocan los comportamientos imprevistos de los alumnos, a las incertidumbres tan poco imaginadas de las situaciones, a la ambivalencia de los afectos y a una fragilidad inesperada del yo docente.

Comienzan progresivamente a comprender que, cuando están en una situación real de enseñanza, compleja, inestable y abierta a presiones de todo tipo, descubren una forma distinta de la formación que hasta el momento desconocían. Advierten que:

Dicha formación está anclada en las realidades de la clase y de la profesión, es personalizada y concuerda con las actividades del lugar en que se ejerce; además, dentro de las coordenadas del lugar y del período, conlleva una interpelación del sujeto respecto a lo que este es, sabe y hace, y respecto a su evolución y a lo que quiere llegar a ser (Baillauques, 2010, pp. 74-75).

En consecuencia, los profesores en formación —respetando las normas, reglamentos, dispositivos y medios establecidos en los contextos de inserciónaspiran a convertirse en sujetos activos de su trabajo, de sus progresos, de sus posicionamientos personales, y observan con preocupación muchos de los juicios y actuaciones que evidencian los profesores del sistema educativo, particularmente aquellos que han debilitado sus compromisos con la docencia.

Probablemente les falte seguir fraguando, a la luz de la experiencia en contextos reales, muchas de sus representaciones respecto a la docencia. Particularmente cuando el profesor en formación cree "que tendrá todo el tiempo necesario para reflexionar sobre su acción; que piensa que el hecho de dominar conocimientos teóricos fragmentarios es la clave de una intervención exitosa y que considera que el éxito profesional será proporcional a su aptitud para activar un programa específico de intervención" (Carbonneau y Hétu, 2010, p. 127).

\section{REFERENCIAS}


El contexto y los actores de la práctica: Estudio sobre la representación del profesor en formación

Altet, M. (2010). La competencia del maestro profesional o la importancia de saber analizar las prácticas. Paquay, L., Altet, M., Charlier, E. y Perrenoud, P. (Coords.). La formación profesional del maestro (pp. 33-48). México: FCE.

Ávalos, B. (2003). La formación docente inicial en Chile. Santiago: Ministerio de Educación.

Baillauques, S. (2010). El trabajo de las representaciones en la formación de los maestros. Paquay, L., Altet, M., Charlier, E. y Perrenoud, P. (Coords.). La formación profesional del maestro (pp. 55-87). México: FCE.

Belair, L. (2010). Enseñar la complejidad del oficio de maestro. Paquay, L., Altet, M., Charlier, E. y Perrenoud, P. (Coords.). La formación profesional del maestro (pp. 88-106). México: FCE.

Carbonneau, M y Hétu, C. (2010). La formación práctica de los maestros y el nacimiento de una inteligencia profesional. Paquay, L., Altet, M., Charlier, E. y Perrenoud, P. (Coords.). La formación profesional del maestro (pp. 107138). México: FCE.

Correa, E., Cividini, M. y Fuentealba, R. (2013). Formación inicial e inserción profesional: procesos clave para la profesionalización docente. Correa, E., Cividini, M. y Fuentealba, R., Boerr, I. Formación e inserción profesional: desafíos y pistas de facilitación para la profesionalización docente (pp. 918). Santiago: SDL Impresores.

Davini, M. (1995). Formación docente en cuestión: política y pedagogía. Buenos Aires: Paidós.

Day, C. (2006). Pasión por enseñar. La identidad personal y profesional del docente y sus valores. Madrid: Narcea.

Diker, G. y Terigi, F. (1997). La formación de maestros y profesores: hoja de ruta. México: Paidós.

Fernández-Cruz, M. (2008). El practicum en la construcción del conocimiento profesional docente. Correa, E., Colette, M., Rittershaussen, S. Vers une conceptualisation de la situation de stage: explorations internationales. Montreal: Editions du CRP. 
El contexto y los actores de la práctica: Estudio sobre la representación del profesor en formación

Flick, U. (2007). Introducción a la investigación cualitativa. Madrid: Morata.

Galaz, A., Fuentealba, R., Cornejo, J. y Padilla, A. (2011). Estrategias reflexivas en la formación de profesores y de formadores de profesores. ¿Qué desafíos se proyectan desde la formación basada en competencias?. Santiago: LOM.

Paquay, L., Altet, M. Charlier, E. y Perrenoud, P. (2010). La formación profesional del maestro. Estrategias y competencias. México: FCE.

Pérez, G. (2007). Investigación cualitativa. Madrid: La Muralla.

Riessman, C. (2008). Narrative Methods for the Human Sciences. Thousand Oaks, New Delhi: Sage.

Schon, D. (2010). La formación de profesionales reflexivos: hacia un nuevo diseño de la enseñanza y el aprendizaje en las profesiones. México: Paidós.

Tardif, M. (2004). Los saberes docente y su desarrollo profesional. Madrid: Narcea.

Tenti, E. (2007). Consideraciones sociológicas sobre profesionalización docente. Educ. Soc., 28 (99), 335-353.

Wanjiru, C. (1999). La ética de la profesión docente. Estudio introductorio a la deontología de la educación. Navarra: EUNSA. 